\title{
Silent Hands: A Leader's Ability to Create Nonverbal Immediacy
}

\author{
Linda Talley \\ Walden University \\ Samuel Temple \\ AT\&T, San Antonio, Texas
}

\begin{abstract}
Nonverbal immediacy is a core element of a leader's ability to lead followers. Nevertheless, there are no empirical studies regarding a link between a leader's hand gestures and followers' perceptions of immediacy (attraction to someone) or nonimmediacy (distancing). Guided by Mehrabian's theory of nonverbal behavior, this study included one independent variable segmented into seven levels (positive hand gestures defined as community hand, humility hands, and steepling hands; three defensive gestures, defined as hands in pocket, arms crossed over chest, and hands behind back; and neutral/no hand gestures) to test for immediacy or nonimmediacy. In this experimental study, participants $(n=300$; male $=164$; female $=143$ ) were shown one of seven pictures of a leader. Four hypotheses were tested for main and interactional effects and all were supported by the results. Immediate communication received strong support, meaning immediacy on the part of a leader is likely to lead to increased emotional connection to achieve desirable outcomes. This study advances theory from previous research that specific hand gestures are more effective than others at creating immediacy between leaders and followers.
\end{abstract}

Keywords: nonverbal communication, nonverbal immediacy, nonverbal nonimmediacy, hand gestures, leader development

\section{Introduction}

The news media has verbalized the meaning of politicians' and corporate leaders' hand gestures during speeches and personal or business interactions. For example, political leaders are encouraged on Internet blogs to use nonverbal communication to make the emotional connection with viewers or followers (Lieberman, 2016). Bloggers and pundits attempt to explain the feelings or perceptions these emotional displays create in the mind of observers. For example, Mehrabian (1971) stated that "people are drawn towards persons or things they like, they evaluate highly and prefer; they avoid or move away from things they dislike, negatively evaluate or do not prefer" (p. 1). Additionally, women are told to display "power poses" for success (Carney, Cady, Yap, 2010); Sandberg (2013), a Facebook executive, told women to act like a man. However, none of these assertions include how followers really perceive a leader.

Historically, the Dr. Fox Lecture, a 1970s academic hoax, included an actor as a leader to present an incoherent speech to several different groups of educators and professionals (Naftulin, Ware, \& Donnelly, 1973). The speech contained conflicting verbal information, yet the viewers rated Dr. Fox favorably due to his appearance as a leader and authority figure: his nonverbal communication. The most notable responses indicated that his ratings were due to the participants' perceptions of his 
relaxed manner during the speech. If a false leader with a poor verbal message can persuade viewers with a relaxed manner, can specific hand gestures be part of this influence? This seems likely, because nonverbal behavior reveals immediacy (an attraction to someone) or nonimmediacy (distancing) in relationships between people, which will be discussed (Mandal, 2014).

Scholars have not focused on ascertaining the meaning or perception of hand gestures. Although some researchers have grouped several hand gestures together, there has yet to be an extensive study of specific hand gestures. Scholars have assumed what specific hand gestures mean (Ambady \& Rosenthal, 1993; Burgoon \& Le Poire, 1999; Maricchiolo, Livi, Bonaiuto, \& Gnisci, 2011), but only one study (Talley \& Temple, 2015) has included specific hand gestures for immediacy and nonimmediacy, or what creates an emotional connection with followers, a critical aspect of motivational leadership (Jia, Cheng, \& Hale, 2016).

This present study focused on Mehrabian's (1971) and Richmond, McCroskey, and Hickson's (2008) nonverbal immediacy theory that suggested that the more nonverbal immediacy (an attraction to someone) a person uses, the more another person will like, positively judge, and prefer to be in proximity to that individual. The less nonverbal immediacy a person uses creates the opposite effect. This theoretical perspective has been supported by Talley and Temple (2015), who maintained that specific groups of hand gestures create immediacy and nonimmediacy. No previous studies have tested individual hand gestures for immediacy, which creates a gap in the literature and is addressed here. In this study, we have built on Richmond et al.'s (2008) theory of immediacy and Talley and Temple's (2015) more contemporary theory that specific hand gestures can create immediacy in and of themselves.

\section{Immediacy Versus Nonimmediacy}

Immediacy and nonimmediacy have been studied in verbal and nonverbal formats (Jia et al., 2016; Mehrabian, 1971; Richmond et al., 2008). Immediacy brings people closer together, whereas nonimmediacy emotionally distances people from one another. Choi, Gray, and Ambady (2009) posited that perceived and interpreted nonverbal communication can be either attracting or distancing; they found that a follower's attraction to a leader is determined based on the leader's nonverbal communication, which is an emotional display (Lewis, 2000).

Richmond et al.'s (2008) theory of immediacy noted that the more a person uses nonverbal immediacy, or positive gestures that were not specifically defined by them, the more viewers will evaluate him or her in a positive manner and prefer to be around him or her. Their research used student participants who assessed teachers who used generalized gestures (gesturing with hands), noting them as positive hand gestures, but nothing more specific. Recent research on nonverbal immediacy has used instructors' credibility and students' satisfaction (Zhu \& Anagondahalli, 2018). Results indicated that the instructor's nonverbal immediacy had a positive influence on his or her credibility. Students' demanding attitudes (student academic entitlement) were mediated by the instructor's nonverbal immediacy and credibility.

Many researchers have studied nonverbal communication like hand gestures in general terms (Beattie \& Shovelton, 1999; Dodds, Mohler, \& Bülthoff, 2011; Ekman \& Friesen, 1969; Iverson \& Goldin-Meadow, 1998; Krauss, 1998; Maricchiolo et al., 2011; Mehrabian, 1971; Wachsmuth, 2006). For instance, Maricchiolo et al. (2011) noted the effects of positive and negative hand gestures but did not further investigate these broad definitions. Gitter, Black, and Walkley (1976) used the terms strong and weak gestures. However, there is a gap when classifying or creating subsets or 
subcategories of iconic hand gestures that create immediacy or nonimmediacy. There is anecdotal evidence for the support of subsets or categories of hand gestures (Pease, 2004), but prior to the current and previous research (Talley \& Temple, 2015), there has been little or no empirical data to support these claims.

Previous researchers have categorized hand gestures as iconic, emblems, or beats (Ekman \& Friesen, 1969; Mehrabian, 1971), but subcategorization of these gestures has not been studied since these categories were introduced. In a previous study, Talley and Temple (2015) operationally defined positive (e.g., community hand, humility hands, and steepling hands), defensive (e.g., hands in pocket, arms crossed over chest, and hands behind back), and no hand gestures (i.e., the absence of noticeable gestures). In this study by Talley and Temple, participants viewed one of three 1-min videos and then completed the Nonverbal Immediacy Scale-Observer Report (NIS-O; Richmond et al., 2008), which had been previously tested and validated. One video had an actor using three positive hand gestures, one showed an actor using three defensive and gestures, and one showed an actor using no hand gestures. Analysis of data indicated that participants perceived leaders with no hand gestures as well as defensive hand gestures to be distant or nonimmediate and a leader with positive hand gestures to be more immediate or attractive. This data led the way to the current research.

The current study was conducted to question whether seven specific hand gestures, as operationalized in a previous study (Talley \& Temple, 2015), individually create meaning: immediacy or nonimmediacy, as perceived by observers. This study is important to the field in that it furthers the study of emotional displays by people using specific hand gestures that are perceived by observers as either positive or negative (Lewis, 2000) and in this study as either immediate or nonimmediate. This study was designed to answer the following research question.

Research Question: Can someone create the emotional connection with observers by using specific hand gestures?

By operationally defining hand gestures for empirical testing, data can be used to show leaders how to make an emotional connection with followers based on using these hand gestures. This study included seven hand gestures (Talley \& Temple, 2015) operationalized for this study and defined as subsets of iconic gestures, as categorized by Ekman and Friesen (1969) and Mehrabian (1971).

To study this, seven pictures of a male chief operating officer (COO) from a major southwest hospital chain were viewed. This study did not use an actor; therefore, no deception was used. Participants were primed in the initial stages of the study by reading a page with a description of the pictures they would be viewing as those of a COO of a major hospital chain. Doyen, Klein, Pichon and Cleeremans (2012) noted that unconscious behavioral priming is real. Pictures are powerful psychological cues (Sundar, 2000) and allowed the independent variable to be studied to test the following hypotheses:

Hypothesis 1: Three specific and individual positive hand gestures are perceived as creating more immediacy than three specific defensive hand gestures and no hand gestures.

Hypothesis 2: Neutral or no hand gestures are perceived as creating more immediacy than the three specific defensive hand gestures.

In the current study, we showed participants $(n=307)$ one of seven pictures of a male COO from a major Southwest hospital chain. The independent variable, hand gestures, consisted of seven levels: 
three individual positive hand gestures, three individual defensive hand gestures, and one with no (i.e., neutral) hand gesture. Seven different photographs of the COO displaying the seven different hand gestures were taken. There was no digital manipulation of the photographs. Physical staging, facial expression, and leader appearance (clothing, background) were held constant, and these were not manipulated. Participants were told in the instructions that this was a picture of a leader of a major health care institution.

It was hypothesized that the following hand gestures are positive:

1. Community hands (the position of the hands show the palm vertical to the ground)

2. Humility hands (hands are clasped in front of the person at waist level)

3. Steepling hands (hands form a steeple with fingertips touching)

See the Appendix for photos.

It was hypothesized that the following hand gestures are defensive:

1. Hands in pockets (both hands are in the leader's pants pockets)

2. Crossed arms (both arms are crossed over the chest)

3. Hands behind back (hands are clasped behind the back)

No hand gestures, the seventh level of the independent variable, was defined as the leader in the photo keeping his hands at his side. It was hypothesized that this is a neutral position and participants would have a neutral response-participants would not like this gesture as much as the positive hand gestures, but they like it more than the defensive hand gestures. Another reaction could have been that no hand gesture is perceived as less attractive than the positive hand gestures and more attractive than the defensive hand gestures.

\section{Method}

Participants $(n=307 ;$ male $=164$, female $=143)$ were recruited from Amazon's Mechanical Turk (MTurk) website for this study. Previous research has noted the use of this source (Casler, Bickel, \& Hackett, 2013; Goodman, Cryder, \& Cheema, 2013) that produces data equivalent to university undergraduate populations (Paolacci \& Chandler, 2014) and is more indicative of Westernized populations (Berinsky, Huber, \& Lenz, 2012). When using a short questionnaire-based study, data generated via MTurk is equivalent to university-based student populations and provide participants who more readily represent a United States based population and create more generalizable results. Subject inattentiveness is a threat to internal and construct validity. Hauser and Schwarz (2016) noted that MTurk participants were more attentive than traditional subject pool samples.

Participants were located mainly in the United States and Canada and reported 1,000 hits (jobs, tasks, or activities) completed with a $99 \%$ or above approval ranking. Ages ranges from 18 to $68, M=$ 35. Age and gender were included in the analysis to check for demographics even though there was no hypothesis including this information.

Seven different pictures of a COO were used for manipulation of the seven levels of the independent variable. All seven pictures included the same $\mathrm{COO}$ varying only in the use of hand gesture levels as defined by the experiment. The $\mathrm{COO}$ was dressed the same for all pictures; the pictures were shot from the head to the knees. In Group 1, participants viewed the $\mathrm{COO}$ with crossed his arms over his chest $(n=44)$; in Group 2, participants viewed the COO using community hands $(n=44)$; in Group 3 , 
participants viewed the $\mathrm{COO}$ with his hands behind his back $(n=47)$; in Group 4, participants viewed the $\mathrm{COO}$ with his hands in his pockets $(n=43)$; in Group 5, participants viewed the COO with his hands in the humility position-clasped in front of him $(n=44)$; in Group 6, participants viewed the $\mathrm{COO}$ with his hands at his side (no hands; $n=43$ ); and in Group 7, participants viewed the COO using steepling hands $(n=42)$.

The survey and seven pictures were uploaded to Amazon MTurk. After viewing the picture, participants completed the NIS-O (Richmond et al., 2008), which had been previously tested and validated (McCroskey \& McCain, 1974; Richmond et al., 2008). The NIS-O was shown to have excellent reliability on this sample $(\alpha=.95)$.

The instrument includes a 5-point Likert scale (ordinal), ranging from 1 (never) to 5 (very often) as responses and total scores ranging from -52 to 52 . This instrument is used to measure peoples' attraction towards people they like or distancing themselves from people they do not like or prefer (Mehrabian, 1971).

The NIS-O instrument (Richmond et al., 2008) includes 26 questions. A sample question from the instrument is this: "He uses her/his hands and arms to gesture while talking to people." This assessment provided the participant the opportunity to assess the hand gestures of a leader and then make an evaluation or judgment of feelings based on immediacy or nonimmediacy (attraction or distancing). Using the scoring rubric, participants' scores were tabulated to provide a summative score for data analysis. A significance level of .05 was selected, a priori, to provide a $95 \%$ confidence level for hypotheses testing.

Questions were used to determine the degree of immediacy from participants and how participants perceived the leader's hand gestures. Per the design of the questionnaire, Items 1, 2, 6, 10, 12, 13, 14, $16,17,19,21,22$, and 25 in the NIS-O were used to assess the participants' immediacy to the leader. All remaining items were used to measure participants' nonimmediacy to the leader. The sum of nonimmediacy items was subtracted from the sum of immediacy items for a total immediacy score.

\section{Results}

A two-way analysis of covariance yielded a main effect for each picture view, $F(6,298)=13.23$, $p<.0001$. Post hoc analysis using Tukey least significant difference pairwise comparisons test (Table 1) revealed that all three positive hand gestures (community, humility, and steepling) resulted in significantly higher NIS-O scores than the three different defensive hand gestures (back, crossed, and pocket) at $p<.05$, and there were no significant differences observed among the three positive gestures or among the three negative gestures. Hypotheses 1 and 2 were confirmed. Neither of the main effects for gender was significant, $F(1,298)=.01, p=.9223$, nor was the covariate for age $F(1,298)=2.09 p=.1496$.

This study empirically establishes that positive hand gestures do create immediacy by observers and positive and defensive hand gestures can be separately studied as different levels of the independent variable. The data established individual categories for seven specific and individual hand gestures as either immediate or nonimmediate. Levine's test indicated equal variances across all groups $F(6,300)=1.78, p=.1037$. The NIS-O was shown to have excellent reliability on this sample $(\alpha=$ $.95)$. 
Table 1. Tukey Least Significant Difference Pairwise Comparisons

\begin{tabular}{lccc} 
Pairwise Comparison & Mean Difference & $\boldsymbol{S D}$ & $\boldsymbol{p}$ \\
\hline Crossed hands: Community hands & -17.69 & 10.40 & $<.01$ \\
Crossed hands: Hands behind back & 5.35 & 10.23 & .71 \\
Crossed hands: Hands in pocket & -0.24 & 10.45 & 1.00 \\
Crossed hands: Humility hands & -10.93 & 10.39 & .03 \\
Crossed hands: Neutral & -0.95 & 10.46 & 1.00 \\
Crossed hands: Steeple hands & -15.99 & 10.54 & $<.01$ \\
Community hands: Hands behind back & 23.04 & 10.23 & $<.01$ \\
Community Hands: Hands in pocket & 17.45 & 10.46 & $<.01$ \\
Community hands: Humility hands & 6.76 & 10.40 & .46 \\
Community hands: Neutral & 16.75 & 10.49 & $<.01$ \\
Community hands: Steeple hands & 1.70 & 10.58 & 1.00 \\
Hands behind back: Hands in pocket & -5.59 & 10.29 & .67 \\
Hands behind back: Humility hands & -16.28 & 10.22 & $<.01$ \\
Hands behind back: Neutral & -6.29 & 10.30 & .54 \\
Hands behind back: Steeple hands & -21.34 & 10.38 & $<.01$ \\
Hands in pocket: Humility hands & -10.69 & 10.45 & .04 \\
Hands in pocket: Neutral & -0.70 & 10.52 & 1.00 \\
Hands in pocket: Steeple hands & -15.75 & 10.60 & $<.01$ \\
Humility hands: Neutral & 9.98 & 10.46 & .07 \\
Humility hands: Steeple hands & -5.06 & 10.54 & .79 \\
Neutral: Steeple hands & -15.04 & 10.58 & $<.01$ \\
\hline
\end{tabular}

\section{Discussion}

People are moved by an emotional appeal created by the leakage of emotional states via nonverbal communication or gestures (Buck \& Van Lear, 2002). When someone displays his or her emotions using hand gestures, the observer perceives these leakages as creating immediacy or not (Talley \& Temple, 2015). People may not be aware of what their hand gestures are saying, what message they are conveying to observers, or how this affects the perception of observers (Goleman, 1998; Lewis, 2000).

Little research prior to Talley and Temple (2015) has included the study of a leader's specific hand gestures and how it impacts immediacy or nonimmediacy. This research has shown that the more positive, open hand gestures that a leader uses, the more attraction he or she creates with followers. The more defensive hand gestures or no hand gestures a leader uses, the more distance she or he will create with followers. When people are aware of which gestures they are using and how this impacts those around them, they can choose gestures that support the verbal message and create congruence among those around them. Certainly, different situations call for the use of different hand gestures and the meaning one wants to create. 
It is easy for a leader to perceive the emotions of an observer to ascertain an emotional connection, but the leader must give attention to his or her own nonverbal communication and the effect on immediacy and nonimmediacy with followers. If an individual is to increase the emotional connection with observers to create change, that leader must understand the perception (immediacy or nonimmediacy) his or her hand gestures create.

Previous research included general hand gesture groupings to study immediacy and nonimmediacy (Jia et al., 2016, Mehrabian, 1971, Richmond et al., 2008). Although these general groupings of hand gestures noted immediacy and nonimmediacy, the next logical step was to look at individual and specific hand gestures. The purpose of this study was to provide empirical evidence to support a new theory: Certain individual hand gestures create more immediacy between a leader and observers. Based on previous research (Talley \& Temple, 2015), we identified three specific hand gestures (community, humility, and steepling hands) that outperformed the three defensive hand gestures (arms crossed, hands behind back, hands in pocket) and no hand gestures.

Operationalized hand gesture groups have been previously studied for use by leaders (Talley \& Temple, 2015) and were tested individually, as seven levels of the independent variable, and revealed what a leader can do with his or her hands to create immediacy and/or minimize feelings of nonimmediacy by regulating or eliminating no hand gestures and three specific defensive hand gestures from interaction with followers.

By focusing on individual hand gestures, a leader can see how regulating hand gestures can change the perception of observers and either create immediacy or nonimmediacy. Prior to this study and the work of Talley and Temple (2015), there was no indication that specific hand gestures created meaning for the observer. An executive coach or training program can assist the leader in identifying hand gestures used, based on this research, that minimize the leader's emotional connection and, therefore, his or her ability to influence and achieve results and also those gestures that create influence beyond positional power (Dagley \& Gaskin, 2014).

A methodology has been provided to create nonverbal immediacy with observers by using specific hand gestures. The effective leader, with or without title, constantly seeks ways to manage the perception of followers and observers to create the emotional connection and immediacy to achieve goals and results. With this information, an individual can choose which perception he or she wants to create-immediacy or nonimmediacy - thereby managing observer perception as discussed by Druckman et al. (1982) and, ultimately, the relationship with those around them. Leaders can now use this information to understand and manage the message they are sending nonverbally to those around them.

\section{Recommendations for Future Study}

This study is the next logical step to expanding research to create a better understanding of nonverbal behavior, regarding hand gestures and observer perception. The robust results of this study create a foundation upon which future study recommendations will add to the knowledge and meaning of these specific and individual hand gestures and also of future operationalized hand and leg gestures.

Although the sample's demographics allowed gender and age to be considered as a covariate with a male leader, they showed no significance, but a future study might consider a female leader to study and test for significance. Research by Butler and Geis (1990) showed that female leaders are 
perceived more negatively than male leaders when using transactional leadership. A future study may ask if a female leader's hand gestures could change this perception.

Some of the research cited in this article used college students as participants. This study as well as Talley and Temple (2015) used MTurk participants who could be considered employed or selfemployed participants. In other words, these were working participants, not students (who may or may not be employed or self-employed), and we can therefore generalize these results to a business population. Future research should continue to use business-oriented participants to maintain generalization efficacy.

The current study was composed mainly of MTurk participants from the United States and a small percentage from Canada. These two countries are considered individualistic cultures (Hofstede, 1983). Although the current sample was not culturally diverse, a future study might explore the contribution of these demographic factors to determine if specific hand gestures cross cultural boundaries.

\section{Conclusion}

The purpose of this study was to investigate individual hand gestures of a leader to determine meaning as perceived by observers. The study confirms that some specific and individual hand gestures may be more effective than others in creating immediacy or nonimmediacy and provides the foundation for continued development of leaders in the area of social skills such as nonverbal communication. This study provides leaders with information that informs their interaction with those around them and/or with clients to be a more effective communicator and leader. Not only does this data inform leaders of specific skills that can be developed to create nonverbal immediacy, it may add to their personal and professional development level, particularly for the competency of effective communication, and may increase their level of emotional intelligence (Riggio \& Reichard, 2008).

Organizations and external as well as internal coaches can use this empirical evidence to support training in the area of nonverbal communication skills in leader development programs for fast track emerging leaders or remedial purposes. Executive coaches can use this evidence to support their interpersonal interaction with clients and, at the same time, inform clients of the importance of using specific hand gestures.

A leader's true genius is in his or her ability to connect with followers. It is the emotional connection that creates the relationship of immediacy or nonimmediacy among leader and followers. The dialogue among leaders and observers should not consist of solely the use and understanding of words. This study empirically demonstrates that nonverbal behavior, specifically a leader's hand gestures, creates immediacy or nonimmediacy in dialogue.

\section{References}

Ambady, N., \& Rosenthal, R. (1993). Half a minute: Predicting teacher evaluations from thin slices of nonverbal behavior and physical attractiveness. Journal of Personality and Social Psychology, 64, 431-441.

Beattie, G., \& Shovelton, H. (1999). Do iconic hand gestures really contribute anything to the semantic information conveyed by speech? An experimental investigation. Semiotica, 123, $1-30$. 
Berinsky, A. J., Huber, G. A., \& Lenz, G. S. (2012). Evaluating online labor markets for experimental research: Amazon.com's Mechanical Turk. Political Analysis, 20, 351-368.

Buck, R., \& Van Lear, C. A. (2002). Verbal and nonverbal communication: distinguishing symbolic, spontaneous, and pseudo-spontaneous nonverbal behavior. Journal of Communication, 52, 522-541. doi:10.1111/j.1460-2466.2002.tb02560.x.

Burgoon, J. K., \& Le Poire, B. A. (1999). Nonverbal cues and interpersonal judements: Participant and observer perceptions of intimacy, dominance, composure, and formality. Communication Monographs, 66, 105-124.

Butler, D., \& Geis, F. L. (1990). Nonverbal affect responses to male and female leaders: Implications for leadership evaluations. Journal of Personality and Social Psychology, 58(1), 48-59.

Carney, D., Cady, A., Yap, A. (2010). Power posing: Brief nonverbal displays affect neuroendocrine levels and risk tolerance. Psychological Science, 21, 1363-1368.

Casler, K., Bickel, L., \& Hackett, E. (2013). Separate but equal? A comparison of participants and data gathered via Amazon's MTurk, social media, and face-to-face behavioral testing, Computers in Human Behavior, 29, 2156-2160. doi:10.1016/j.chb.2013.05.009

Choi, Y. S., Gray, H. M., \& Ambady, N. (2009). The glimpsed world: Unintended communication and unintended perception. In M. L. Knapp \& J. A. Hall (Eds.), Nonverbal communication in human interaction (pp. 309-333). Boston, MA: Wadsworth, Cengage.

Dagley, G. R., \& Gaskin, C. J. (2014). Understanding executive presence: Perspectives of business professionals. Consulting Psychology Journal: Practice and Research, 66, 197-211. doi:10.1037/cpb0000011

Dodds, T. J., Mohler, B. J., \& Bülthoff, H. H. (2011). Talk to the virtual hands: Self-animated avatars improve communication in head-m ounted display virtual environments. PLoS ONE, 6, 257259. doi: 10.1371/journal.pone.0025759.

Doyen, S., Klein, O., Pichon, C. L., \& Cleeremans, A., (2012). Behavioral priming: It's all in the mind, but whose mind? PLoS ONE 7, e29081. doi:10.1371/journal.pone.0029081

Druckman, D., Rozelle, R. M., \& Baxter, J. C. (1982). Nonverbal communication: Survey, theory, and research (Vol. 139). Beverly Hills, CA: Sage.

Ekman, P., \& Friesen, W. V. (1969). The repertoire of nonverbal behavior: Categories, origins, usage, and coding. Semiotica, 1, 49-98.

Gitter, A. G., Black, H., \& Walkley, J. (1976). Nonverbal communication and the judgment of leadership. Psychological Reports, 39, 1117-1118. doi:10.2466/pr0.1976.39.3f.1117

Goleman, D. (1998). Working with emotional intelligence. New York, NY: Bantam Books.

Goodman, J. K., Cryder, C. E., \& Cheema, A. (2013). Data collection in a flat world: The strengths and weaknesses of Mechanical Turk samples. Journal of Behavioral Decision Making, 26, 213-224. doi:10.1002/bdm.1753

Hauser, D. J., \& Schwarz, N. (2016). Attentive Turkers: MTurk participants perform better on online attention checks than do subject pool participants. Behavioral Research Methods, 48, 400407. doi:10.3758/s13428-015-0578-z

Hofstede, G. (1983). National cultures in four dimensions: A research-based theory of cultural differences among nations. International Studies of Man \& Organizations, 13, 46-74.

Iverson, J. M., \& Goldin-Meadow, S. (1998). Why people gesture when they speak. Nature, 396, 228. 
Jia, M., Cheng, J., \& Hale, C. L. (2016). Workplace emotion and communication: Supervisor nonverbal immediacy, employees' emotion experience, and their communication motives. Management Communication Quarterly, 31, 69-87. doi:10.1177/0893318916650519

Krauss, R. M. (1998). Why do we gesture when we speak? Current Directions in Psychological Science, 7, 54-59.

Lieberman, R. S. (2016). What top leaders can teach about nonverbal communication. Retrieved from https://journal.thriveglobal.com/what-top-leaders-can-teach-about-nonverbal-communicationf19e920ca 482

Lewis, K. M. (2000). When leaders display emotion: How followers respond to negative emotional expression of male and female leaders. Journal of Organizational Behavior, 21, 221-234.

Mandal, F. B., (2014). Nonverbal communication in humans. Journal of Human Behavior in the Social Environment, 24, 417-421. doi:10.1080/10911359.2013.831288

Maricchiolo, F., Livi, S., Bonaiuto, M., \& Gnisci, A. (2011). Hand gestures and perceived influence in small group interaction. The Spanish Journal of Psychology, 14, 755-764.

McCroskey, J. C., \& McCain, T. A. (1974). The measurement of interpersonal attraction. Speech Monographs, 41, 261-266.

Mehrabian, A. (1971). Silent messages (1st ed.). Belmont, CA: Wadsworth.

Naftulin, D. H., Ware, J. E., \& Donnelly, F. A. (1973). The Doctor Fox lecture: A paradigm of educational seduction. Journal of Medical Education, 48, 630-635.

Paolacci, G., \& Chandler, J. (2014). Inside the Turk: Understandings the Mechanical Turk as a participant tool. Current Directions in Psychological Science, 23, 184-188.

Pease, A. (2004). The definitive book of body language. New York, NY: Bantam.

Richmond, V. P., McCroskey, J. C., \& Hickson, M. L. (2008). Nonverbal behavior in interpersonal relations (6th ed.). Boston, MA: Allyn and Bacon.

Riggio. R. E., \& Reichard, R. J. (2008). The emotional and social intelligences of effective leadership:

An emotional and social skill approach. Journal of Managerial Psychology, 23,169-185. doi:10.1108/02683940810850808

Sandberg, S. (2013). Lean in. New York, NY: Knopf.

Sundar, S. S. (2000). Multimedia effects on processing and perception of online news: A study of picture, audio, and video downloads. Journalism \& Mass Communication Quarterly, 77, 480499.

Talley, L. \& Temple, S. (2015). How leaders influence followers through the use of nonverbal communication. Leadership \& Organizational Development Journal, 36, 69-80.

Wachsmuth, I. (2006). Gestures offer insgiht. Scientific American Mind, 17, 20-25.

Zhu, L., \& Anagondahalli, D. (2018). Predicting student satisfaction: The role of academic entitlement and nonverbal immediacy. Communication Reports, 31, 41-52.

[Appendix follows] 
Appendix

\section{Pictures of Hand Gestures}

\section{Defensive Gestures}
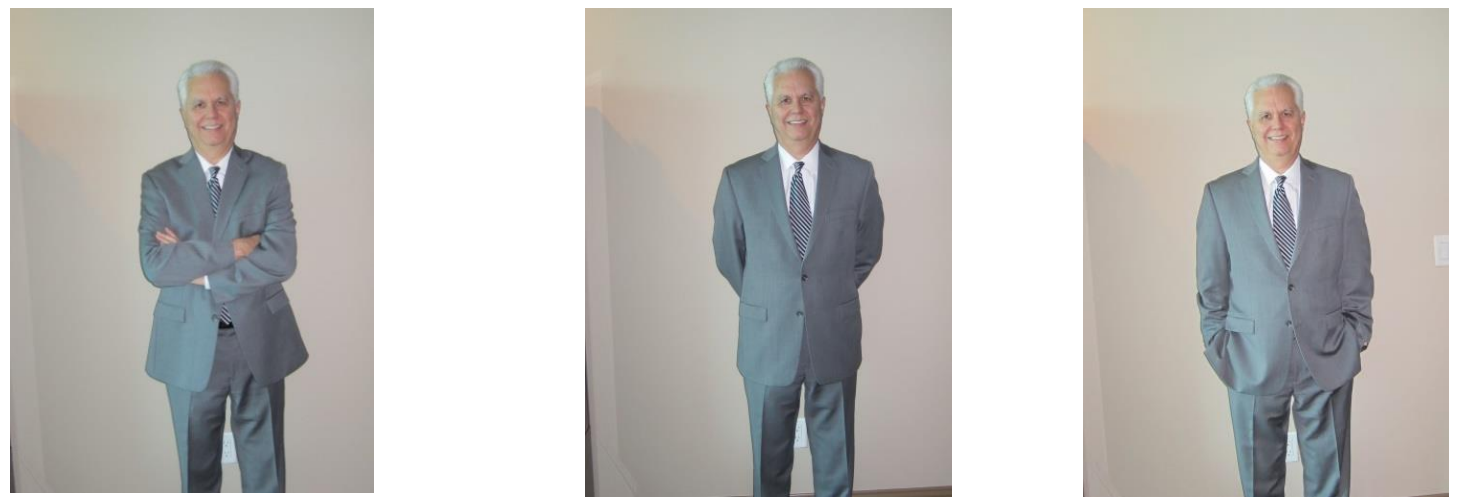

\section{Positive Gestures}
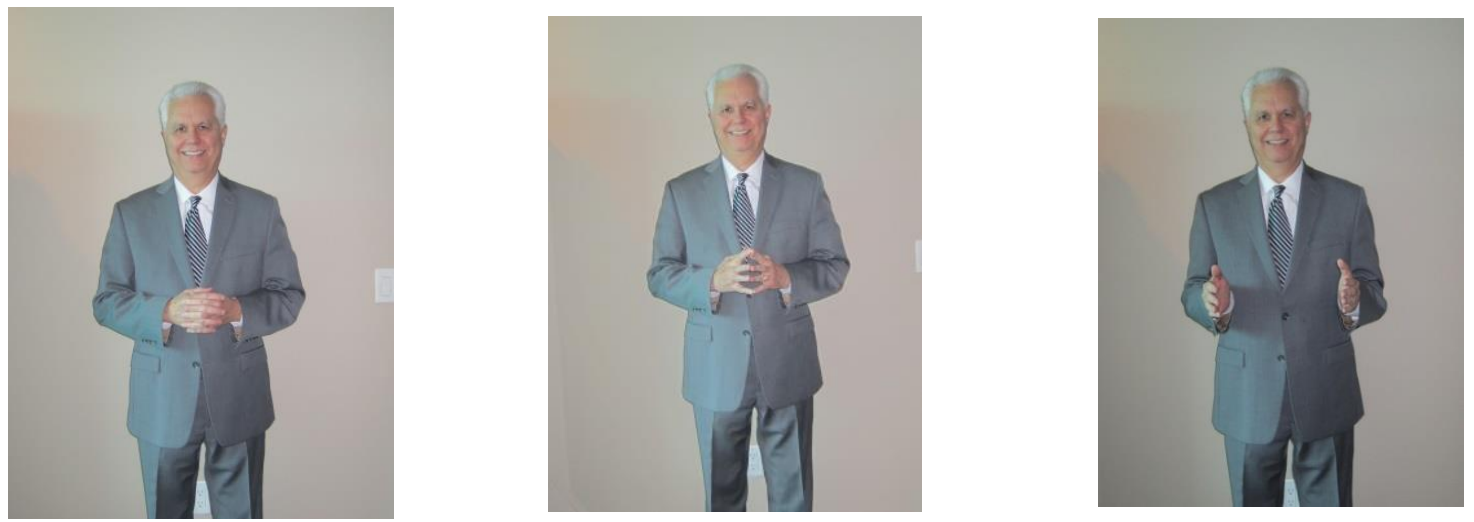

\section{No Gestures}

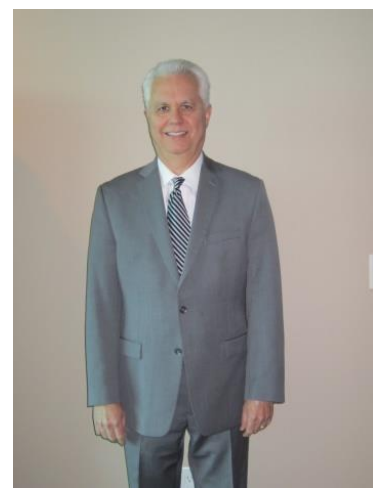


The Journal of Social, Behavioral, and Health Sciences is an open-access, peer-reviewed, online interdisciplinary journal focusing on research findings that address contemporary national and international issues. Its objectives are to (a) encourage dialogue between scholars and practitioners in the social, behavioral, and health sciences that fosters the integration of research with practice; (b) promote innovative models of interdisciplinary collaboration among the social, behavioral, and health sciences that address complex social problems; and (c) inform the relationship between practice and research in the social, behavioral, and health sciences.

Walden University Publishing: http://www.publishing.waldenu.edu 